\title{
Hydrothermal Treatment of Postconsumer Aseptic Packaging Material: Solid Fuel Production and Aluminum Recovery
}

\author{
Baskoro Lokahita, Kunio Yoshikawa, Fumitake Takahashi \\ "Department of Environmental Science and Technology, Tokyo Institute of Technology, Yokohama 226-8502, Japan"
}

\begin{abstract}
In this study, Tetra Brik from Tetra Pak Company was used to produce solid fuel. Tetra Brik consists of paper, LDPE, and Aluminum arranged in 6 different layers. Aluminum should be recovered to obtain high-quality solid fuel. Hydrothermal treatment was used to separate aluminum from the solid fuel. Temperature and time were controlled and observed to get the best result. The temperature was varied between $200{ }^{\circ} \mathrm{C}$ and $240{ }^{\circ} \mathrm{C}$, while time was ranged from 0 and 60 minutes. The result showed that composite of aluminum and LDPE was formed in the process, and full separation occurred in the experiment other than $200{ }^{\circ} \mathrm{C}$ in 0 minutes. Ultimate and Proximate analysis were done to understand solid fuel characteristic. As the temperature and time got higher, the calorific value also increase.
\end{abstract}

(C) 2017 The Authors. Published by Elsevier Ltd. This is an open access article under the CC BY-NC-ND license (http://creativecommons.org/licenses/by-nc-nd/4.0/).

Peer-review under responsibility of the scientific committee of the 8th International Conference on Applied Energy.

Keywords: hydrothermal, solid fuel, tetra pak, recycling

\section{Introduction}

As one of the largest food packaging company on the planet earth, Tetra Pak has served more than 175 countries and produced around 180 billion packs annually, means that almost all inhabitant area in the world whether rural or urban region have this product. The arrangement of paper, LDPE, and aluminum form an aseptic environment and gives protection for the food inside and prolong the lifetime of the product. Despite those advantages of Tetra Pak, their rapid production leads to the rise of their post-consumer product. Less than $25 \%$ of their product are recycled every year [1]. The problem is no ordinary machinery could separate the paper, LDPE, and aluminum thus makes it hard to recycle.

\footnotetext{
* Corresponding author. Tel.: +81-45-924-5507 ; fax: +81-45-924-5518 .

E-mail address: lokahita.b.aa@m.titech.ac.jp .
} 
For the one-liter package, the weight is only 28 grams although consist of 6 layers. From outside to inside, the first layer of Tetra Pak is LDPE, which is used to protect the printed brand and information and to abide from damp and bacteria. The second layer is paper, primary material of Tetra Pak, which gives support and rugged structure to the packaging, and media to print the brand and information of the product. The third layer is thin polyethylene to bond paper and aluminum. The fourth layer is aluminum, which gives protection against UV rays, oxygen, odor and bacteria. It also helps to preserve the temperature of the product. The fifth layer is another thin polyethylene to bind aluminum and inner LDPE. The last layer is LDPE to seal the product thoroughly and make sure there is no leak in the packaging. The high temperature was used to stick all of the layers together, which means no glue or adhesive is needed. The paper sheet did not have direct contact with liquid inside. Therefore, the quality of the paper will always as good as new [2].

Tetra Pak uses virgin fiber for the paper. In South America, Europe, Africa and Asia, they used the unbleached duplex board from sulfate pulp. Occupying over $70 \%$ of the whole packaging, those fibers is an excellent source of solid fuel as they possess the quality of virgin wood [3].

As the global energy demand rises, the needs of alternative fuels also increase. Biomass has been one of potential renewable energy sources. Hydrothermal Treatment is a process utilizing steam under high pressure and temperature to destroy biomass chain to become a product with high calorific value. Hydrothermal Treatment possesses wide scalability range from the portable reactor into power plant size reactor, makes it easier to use this treatment to process material according to user's needs. Hydrothermal treatment gives advantages to converting biomass into solid fuel by avoiding an energy -extensive drying process, high conversion efficiency and relatively low operation temperature compare to other thermal methods [4,5]. Hydrothermal treatment is also applicable to process inorganic waste such as plastic, fabric, and rubber. On poly-vinyl-chloride (PVC), about $96 \%$ of its inorganic chlorine could be reduced in the washing process after hydrothermally treated at temperature $255^{\circ} \mathrm{C}[6]$.

The research on Hydrothermal Treatment of Tetra Brik Postconsumer wastes to produce solid fuel has not been conducting yet. Most studies focused on separation of paper, aluminum and LDPE using hydropulper which produces paper fibers and composite of polyethylene and aluminum. The composite then goes to separation process again using an organic solvent. Those processes take a long time and require chemical $[2,3,7,8]$. By this study, alternatives on processing Tetra Brik waste is given. The aim of this work is to produce high-quality solid fuel and separate the material in each layer of Tetra Brik product. This work will focus on characterization of product from Hydrothermal Process using ultimate and proximate analysis to understand the potential as a solid fuel source.

\section{Experimental}

Tetra Brik sample employed in this work was obtained from Tetra Pak Japan. Tetra Pak Japan collects Tetra Pak waste from municipalities to be recycled in their plant. The sample was received in open and clean condition. The sample then chipped into about $1 \mathrm{~cm} 2$ using scissors then dried overnight.

Hydrothermal Treatment was carried out in lab scale reactor series MMJ-500 made by OM Lab-tech Co., Ltd., Japan. The reactor vessel is made of glass with $500 \mathrm{ml}$ of volume capacity. Motor stirrer, pressure gauge, and PID Temperature Controller was equipped in the reactor.

9 grams of solid samples mixed with 81 grams of distilled water was constantly used for all experiment The reactor was sealed, purged with argon, then heated to $200-240 \mathrm{C}$ by the electric heater for 0-60 minutes. The pressure was not controlled but monitored from pressure gauge. The motor stirrer was set at 400 RPM.

After the reaction is finished and reactor cooled down to $80 \mathrm{C}$. The sample was discharged from the reactor to be dried at $105 \mathrm{C}$ overnight. Dried sample contain two materials; hydrochar and composite of aluminum and polyethylene. Those materials could be separated easily because they are in different phase. After separation, the sample was stored in a sealed bag before characterization. The total of nine 
experiments in different three levels was conducted to understand the effect of time and temperature to the quality of solid fuel.

Ultimate Analysis was performed using Vario Micro Cube Elemental Analyzer (Elementary, Germany). The ultimate correlation by Phicai [9] was used to calculate the higher heating value of the treated sample by dry ash free basis in $\mathrm{MJ} / \mathrm{kg}$.

$$
\mathrm{HHV}=(343.08 \mathrm{C}+424.92 \mathrm{H}+261.98 \mathrm{~N}+27.76 \mathrm{O}) / 1000
$$

The proximate analysis of hydrochar was performed using Shimadzu D60 TGA/DTA Analyzer based on ASTM D3172. The content of aluminum on the composite was analyzed by scanning the cross section of the composite using EDS Analyzer by JEOL. The density of the composite of aluminum and polyethylene was calculated using pycnometer and analytical balance.

\section{Result and discussion}

\subsection{Effect of hydrothermal treatment on fuel properties}

Table 1 shows the results of the ultimate analysis, proximate analysis and high heating value (HHV). During hydrothermal treatment dehydration, hydrolysis, and decarboxylation occurs, modify the value of carbon, hydrogen and oxygen. Both time and temperature have the positive effect of increasing the amount of fixed carbon, carbon content, and HHV. Meanwhile, volatile matter, hydrogen, and oxygen decrease as the material decompose during the hydrothermal treatment.

The significant change happened under the holding temperature of $240{ }^{\circ} \mathrm{C}$; the calorific value rapidly increases from $19 \mathrm{MJ} / \mathrm{kg}$ to $25 \mathrm{MJ} / \mathrm{kg}$. Meanwhile, at $200^{\circ} \mathrm{C}$ and $220^{\circ} \mathrm{C}$, there are no significant increases in calorific value with difference less than 0.5 between each experiment. This behavior shows that effect of temperature is greater than time in the experiment and in agreement with the literature [10].

Table 1. Ultimate, proximate, and HHV analysis of hydrochar of Hydrothermally treated Tetra Brik waste and selected fuels for comparison

\begin{tabular}{|c|c|c|c|c|c|c|c|c|c|}
\hline \multicolumn{2}{|c|}{ Experiment Parameters } & \multicolumn{4}{|c|}{ Ultimate Analysis (\%), dry ash free } & \multicolumn{3}{|c|}{ Proximate analysis, Mass fraction (\%) } & \multirow{2}{*}{$\begin{array}{c}\mathrm{HHV} \\
{[\mathrm{MJ} / \mathrm{kg}]}\end{array}$} \\
\hline $\begin{array}{l}\text { Temperature } \\
\left({ }^{\circ} \mathrm{C}\right)\end{array}$ & $\begin{array}{l}\text { Time } \\
\text { (minutes) }\end{array}$ & $\mathrm{C}$ & $\mathrm{H}$ & $\mathrm{N}$ & $\mathrm{O}$ & $\begin{array}{l}\text { Volatile } \\
\text { Matter }\end{array}$ & $\begin{array}{l}\text { Fixed } \\
\text { Carbon }\end{array}$ & Ash & \\
\hline 200 & 0 & $43.67 \%$ & $6.15 \%$ & $0.10 \%$ & $42.91 \%$ & $94.83 \%$ & $1.00 \%$ & $4.17 \%$ & 18.81 \\
\hline 200 & 30 & $43.15 \%$ & $5.68 \%$ & $0.12 \%$ & $48.95 \%$ & $94.67 \%$ & $1.82 \%$ & $3.51 \%$ & 18.61 \\
\hline 200 & 60 & $43.55 \%$ & $5.93 \%$ & $0.18 \%$ & $44.82 \%$ & $92.35 \%$ & $3.17 \%$ & $4.48 \%$ & 18.75 \\
\hline 220 & 0 & $42.91 \%$ & $5.92 \%$ & $0.15 \%$ & $47.81 \%$ & $91.39 \%$ & $3.57 \%$ & $5.04 \%$ & 18.60 \\
\hline 220 & 30 & $44.99 \%$ & $5.85 \%$ & $0.18 \%$ & $44.82 \%$ & $87.44 \%$ & $8.38 \%$ & $4.18 \%$ & 19.21 \\
\hline 220 & 60 & $46.01 \%$ & $5.49 \%$ & $0.16 \%$ & $45.10 \%$ & $82.07 \%$ & $14.67 \%$ & $3.26 \%$ & 19.41 \\
\hline 240 & 0 & $45.18 \%$ & $5.66 \%$ & $0.23 \%$ & $44.85 \%$ & $82.18 \%$ & $9.39 \%$ & $8.43 \%$ & 19.21 \\
\hline 240 & 30 & $59.94 \%$ & $4.27 \%$ & $0.19 \%$ & $27.82 \%$ & $57.58 \%$ & $39.48 \%$ & $2.95 \%$ & 23.20 \\
\hline 240 & 60 & $65.72 \%$ & $4.34 \%$ & $0.24 \%$ & $27.48 \%$ & $59.81 \%$ & $35.40 \%$ & $4.79 \%$ & 25.22 \\
\hline \multicolumn{2}{|c|}{ Paper* } & $47.99 \%$ & $6.63 \%$ & $0.14 \%$ & $36.84 \%$ & $7.42 \%$ & $84.25 \%$ & $8.33 \%$ & 20.34 \\
\hline \multicolumn{2}{|c|}{ RDF* } & $39.70 \%$ & $5.78 \%$ & $0.80 \%$ & $27.24 \%$ & $0.47 \%$ & $73.40 \%$ & $26.13 \%$ & 17.04 \\
\hline \multicolumn{2}{|c|}{ Wood* } & $48.77 \%$ & $5.76 \%$ & $0.27 \%$ & $39.53 \%$ & $15.23 \%$ & $79.23 \%$ & $5.54 \%$ & 20.35 \\
\hline
\end{tabular}




\begin{tabular}{ccccccccc} 
Coal* & $87.52 \%$ & $4.26 \%$ & $1.25 \%$ & $1.55 \%$ & $77.00 \%$ & $18.49 \%$ & $4.51 \%$ & 32.21 \\
Lignite* $^{*}[11]$ & $60.97 \%$ & $4.07 \%$ & $1.02 \%$ & $18.50 \%$ & $43.44 \%$ & $42.95 \%$ & $13.69 \%$ & 23.43 \\
\hline
\end{tabular}

Reaction temperature influences carbon present in hydrochar. Experiment in $240{ }^{\circ} \mathrm{C}$ within 60 minutes has the highest heating value amongst another experiment which is also higher than lignite. It shows the possibility of using hydrothermally treated Tetra Brik as co-firing fuel with coal. What big different of $\mathrm{HHV}$ in $240{ }^{\circ} \mathrm{C}$ compare to another experiment temperature was caused by decarboxylation and volatilization of organic which enhances the carbon content.

Table 1 showed that percentage of volatile matter in the hydrochar decreased as the temperature is increased. High volatiles content indicates that hydrochar is easy to ignite. As the temperature increase, the volatile matter will be converted into fixed carbon. In this case, even though the ignition point is decreased, the calorific value will increase. Co-firing of hydrochar with coal will increase the combustion behavior of the process, because of high volatility of hydrochar [12]. Ultimate and proximate analysis from mix paper, $\mathrm{RDF}$, wood, coal and lignin was added for comparison [11].

\subsection{Effect of hydrothermal treatment on composite of aluminum and polyethylene}

During the hydrothermal process, aluminum and polyethylene were detached from the paper due to degradation of polyethylene which acts as laminating and adhesive agent. Aluminum and polyethylene then attracted to each other because of the different in material density with hydrochar and steam. When the temperature is cooling down, the high-density solid polymorph shape composite was formed. The agglomeration start happens in the parameter above $200{ }^{\circ} \mathrm{C}$ with no holding time. There is no clear correlation between the density of the material and the temperature and time reaction (Table 2).

Aluminum concentration in the composite was measured using SEM/EDS JSM-6610LA by JEOL(Ltd.). By exposing cross-sectional of composites to X-ray, the aluminum content of the composite could be predicted. Figure 1. shows the value of the aluminum content of the composite which basically increase the temperature and time rises.

Figure 1. Effect of time and temperature towards aluminum content

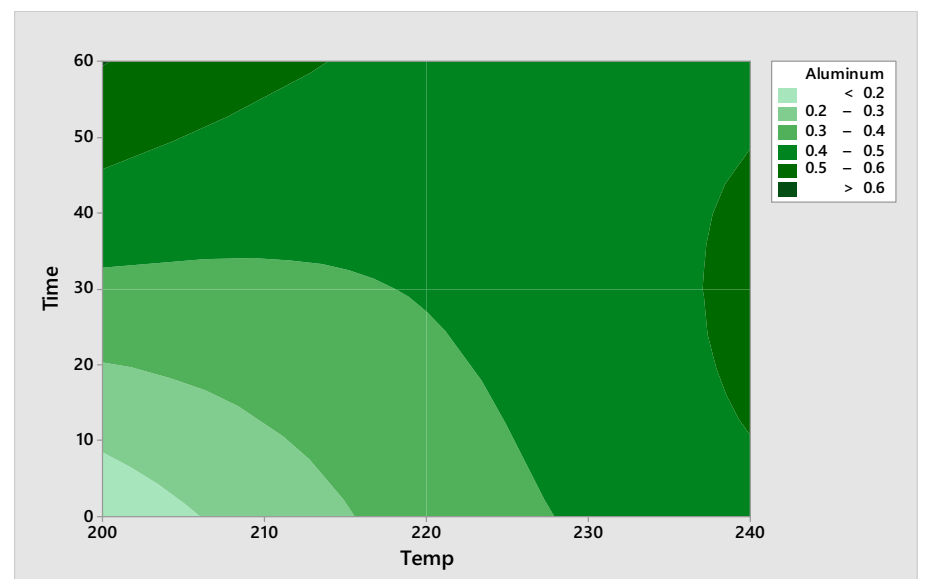

Table 2. Density of Composite of Aluminum and Polyethylene 


\begin{tabular}{ccc}
\hline \multicolumn{2}{c}{ Parameters } & \multirow{2}{*}{ Density $(\mathrm{g} / \mathrm{cm} 3)$} \\
\cline { 1 - 2 } Temp & Time & \\
\hline 200 & 0 & NA \\
200 & 30 & 0.822 \\
200 & 60 & 0.682 \\
220 & 0 & 0.931 \\
220 & 30 & 0.773 \\
220 & 60 & 0.832 \\
240 & 0 & 0.596 \\
240 & 30 & 0.819 \\
240 & 60 & 0.757 \\
\hline
\end{tabular}

Figure 2. Picture of hydrochar and composite after hydrothermal treatment (from left to right; $220^{\circ} \mathrm{C}, 30$ minutes and $240{ }^{\circ} \mathrm{C}$, 0 minutes)

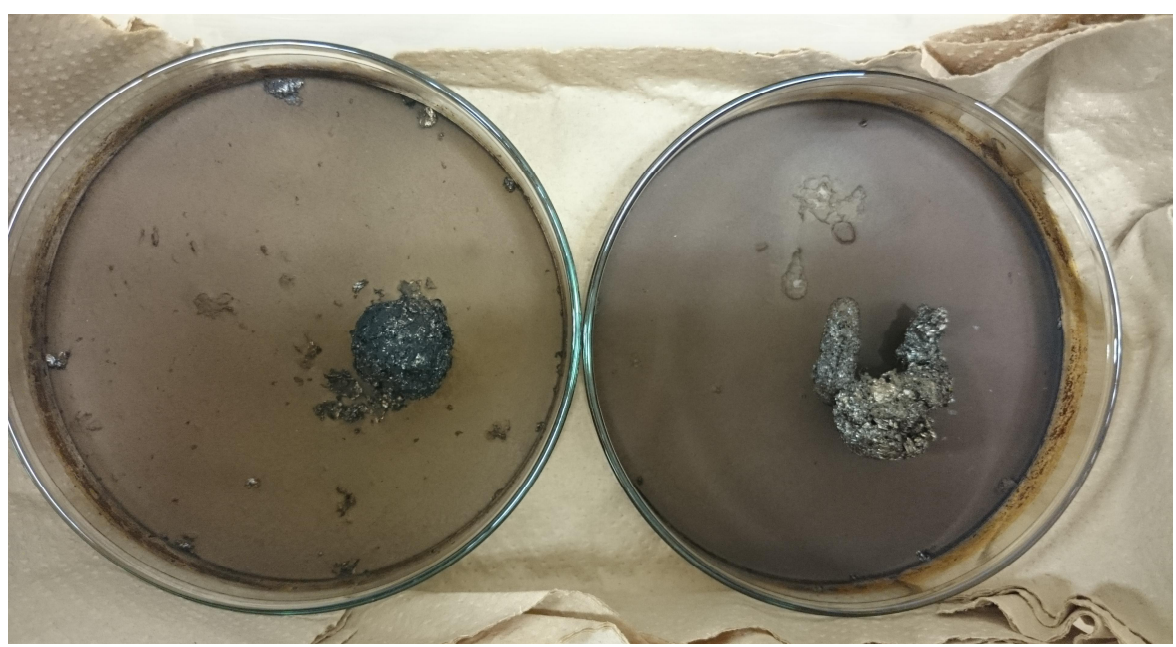

From figure 2, different shape of composite could be observed. Some parameter produces rounder composite than other. The form of the material might be affected by the rotation of the motor and the amount of cooling time. Meanwhile, in higher temperature, darker color of hydrochar is obtained due to increasing of carbon content.

\section{Conclusion}

Hydrothermal Treatment on Tetra Brik was performed to produce solid fuel and recyclable composite material. Characteristic of solid fuel and composite was evaluated. It was observed that the reaction temperature was an important parameter to obtain a solid fuel with high calorific value and composite with high aluminum content. Hydrothermal treatment could increase the HHV of biomass from Tetra Brik up to 25.22 MJ $/ \mathrm{kg}$ which is more than lignite so that possible to do co-combustion with coal. Hydrothermal Treatment also shows effectivity to separate aluminum and polyethylene from paper layer of Tetra Brik. 
Composite produce from the process contains up to $60 \%$ of aluminum. However, practical application of hydrothermal treatment for Tetra Brik recycling process still need further investigation. Binding behavior of composite and polyethylene removal should be studied to obtain a better product.

\section{Copyright}

Authors keep full copyright over papers published in Energy Procedia

\section{Acknowledgment}

The author acknowledges Indonesia Endowment Fund for Education for supporting the doctoral studies of the author. This study was financially supported by JSPS KAKENHI Grant Number 26550059 and 15H04067. The authors appreciated it greatly.

\section{References}

[1] Tetra Laval, Tetra Laval Report 2015-2016; 2015.

[2] J. Zhang, D. Yan, and Z. Li, The Recycling of the Tetra-Pak Packages. 3rd International Conference on Bioinformatics and Biomedical Engineering, Beijing, 2009:1-6.

[3] M. Abreu, Recycling of Tetra Pak Aseptic Cartons; 1999.

[4] P. Zhao, Y. Shen, S. Ge, Z. Chen, and K. Yoshikawa. Clean solid biofuel production from high moisture content waste biomass employing hydrothermal treatment. Appl. Energy 2014;131: 345-367.

[5] P. Prawisudha, T. Namioka, and K. Yoshikawa. Coal alternative fuel production from municipal solid wastes employing hydrothermal treatment. Appl. Energy 2012;90: 298-304.

[6] S. Novianti, A. Nurdiawati, I. N. Zaini, H. Sumida, and K. Yoshikawa. Hydrothermal treatment of palm oil empty fruit bunches: an investigation of the solid fuel and liquid organic fertilizer applications. Biofuels 2016;0:1-10

[7] C. M. A. Lopes and M. I. Felisberti. Composite of low-density polyethylene and aluminum obtained from the recycling of postconsumer aseptic packaging. J. Appl. Polym. Sci 2006;101: 3183-3191.

[8] S. F. Zhang, L. L. Zhang, K. Luo, Z. X. Sun, and X. X. Mei. Separation properties of aluminium-plastic laminates in postconsumer Tetra Pak with mixed organic solvent. Waste Manag Res 2014;32: 317-322.

[9] K. Phichai, P. Pragrobpondee, T. Khumpart, and S. Hirunpraditkoon. Prediction Heating Values of Lignocellulosics from Biomass Characteristics. International Journal of Chemical, Molecular, Nuclear, Materials and Metallurgical Engineering 2013;7: 532-535.

[10] Q. V. Bach, K. Q. Tran, R. A. Khalil, Ø. Skreiberg, and G. Seisenbaeva. Comparative assessment of wet torrefaction. Energy and Fuels 2013;27: 6743-6753.

[11] B. Jenkins, L. Baxter, T. Miles, and T. Miles. Combustion properties of biomass. Fuel Process. Technol1998;54: 17-46.

[12] A. Gani, K. Morishita, K. Nishikawa, and I. Naruse. Characteristics of co-combustion of low-rank coal with biomass. Energy and Fuels 2005;19:1652-1659.

6. Biography
The author is a doctoral student of Tokyo Institute of Technology and also an LPDP Scholarship Awardee. The
author earn his bachelor degree in Institut Technologi Bandung, and master degree in Tokyo Institute of
Technology. He is also an waste management activist in Bandung, Indonesia

